ISSN: 2349-2678

Contents lists available at www.ijpba.in

International Journal of Pharmaceutical and Biological Science Archive

NLM (National Library of Medicine ID: 101738825)

Index Copernicus Value 2019: 71.05

Volume 9 Issue 1; January-February; 2021; Page No. 93-96

\title{
SCREENING \& EVALUATION OF ANTI-DIABETIC SPECTRUM OF WITHANIA COAGULANS
}

\author{
Dr. Mayank Bansal, Sweta Kumari², Mr. Yogesh Kumar Sharma ${ }^{3}$ \\ ${ }^{1}$ Principal, Dr. Mayank bansaI Jaipur College of Pharmacy, Sitapura, Jaipur, Rajasthan -302022 \\ ${ }^{2}$ Student, Jaipur College of Pharmacy, Sitapura, Jaipur, Rajasthan- 302022 \\ ${ }^{3}$ Associate Professor, Jaipur College of Pharmacy, Sitapura, Jaipur, Rajasthan- 302022
}

\section{Conflicts of Interest: Nil}

Corresponding author: Sweta Kumari

DOI https://doi.org/10.32553/ijpba.v9i1.179

\section{ABSTRACT}

Diabetes mellitus is a metabolic disorder. This review article is planned to The anti-diabetic effect of Withania Coagulans have been successfully used in Ayurvedic and other traditional formulations and found to be efficient and inexpensive as compared to synthetic drugs. It also aims to test and verify the W. coagulans fruits, showed significant inhibition on postprandial rise in hyperglycemia post-sucrose load in normoglycemic rats as well as streptozotocin-induced diabetic rats. which is comparable to the standard antidiabetic drug Glibenclamide for medical care, The present study defines the systematic evaluation and the role of minerals in glycemic potential of aqueous extract of Withania coagulans fruits in order to develop an effective and safe alternative treatment for diabetes mellitus.

These studies conducted to determine the antidiabetic effect of Withania coagulans and pancreatic histological features in streptozotocin induced diabetic rat.

Results: The study is based on results of lowering in blood glucose levels of normal, sub, mild diabetic rats assessed during fasting blood glucose, glucose tolerance test studies.

The dose of $1000 \mathrm{mg} / \mathrm{kg}$ was identified as the most effective dose, which reduce the blood glucose level maximum by $35.2 \%$ at 5 hours in normal rats during blood glucose studies.

Glucose tolerance test studies is normal, sub and mild diabetic rats showed the maximum reduction of $16.7,29.8$ and $38.5 \%$ at 4 hour respectively.

Long term study incase of severely diabetic rats showed reduction fasting glucose level respectively after 30 days of treatment.

The present study confirming antidiabetic effect of aqueous extract of Withania Coagulans, helps in identifying the role of trace minerals like $\mathrm{Mg}$ and $\mathrm{Ca}$ responsible for antidiabetic potential of this potent indigenous shrub.

Conclusion: The present research has presented comprehensive details of antidiabetic plants used in the treatment of diabetes mellitus. Most of these plant derived medicines.

Keywords: Anti-Diabetic effect, Screening \& Evaluation, Streptozocin, Glibenclamide, Diabetic rats.

\section{Introduction}

Diabetes mellitus is a metabolic disorder characterized by a predisposition to developing significantly raised blood glucose, caused by the inability of the pancreas to produce insulin or to use the insulin produced in the proper way. Diabetes mellitus has been noted in almost all cultures, Diabetes is a major public health problem.

In normal individuals, glucose concentrations are tightly regulated by a number of hormonal factors. The disordered regulation of glucose metabolism that results in diabetes is usually due to a deficiency of insulin release from the pancreas and a reduced response to insulin.

\section{Etiology}

Type 2 diabetes mellitus (T2DM) is by far the more common type of diabetes and is characterized by insulin resistance resulting from defects in the action of insulin on its target tissues (muscle, liver, and fat), but complicated by varying and usually progressive failure of beta cells' insulin secretary capacity. Most patients with T2DM in the US and Europe are obese, however in India and China, most T2DM patients have a lean body mass index (BMI), albeit with increased visceral and hepatic fat.

\section{Common Causes of Anti-diabetic}

1. sedentary lifestyle

2. obesity (weighing 21 percent above a healthy body weight)

3. family history of diabetes

4. improper functioning of the pancreas

5. minority race (higher risk in Black, Hispanic and native Hawaiian populations)

6. medication (cortisone and some high blood pressure drugs) 
7. Women having given birth to a baby weighing more than 9 lbs.

8. Previously diagnosed gestational diabetes.

\section{Objective}

The use of Withania coagulans, a member of the solanaceae family, has been highlighted in Ayurveda. We have reviewed the chemical constituents and pharmacological properties of W. coagulans, as well as its morphology.

This has included therapeutic effects of the whole plant and its extracts, fractions and isolated withanolides. The Antidiabetic, hepatoprotective, anti-inflammatory, antihyperglycaemic, hypolipidaemic, free radical scavenging, antimicrobial, cardiovascular, central nervous system depressant, immunomodulating, antitumour and cytotoxic activities of $\mathrm{W}$. coagulans have been described.

\section{Material and Method}

- Collection, authentication, storage and size reduction of plant material.

- Standardization of plant material according WHO.

- Extraction of dried fruit of withania coagulans.

- Phytochemical investigation of extract by chemical test.

- TLC analysis of extract.

- Study of anti-diabetic effect of withania coagulans of various dose of different model.

- Study of anti-diabetic activity of various doses of withania coagulans by in vivo model.

- W. coagulans Dunal, is commonly known as 'Indian cheese maker' or 'vegetable rennet' because fruits and leaves of this plant are used as a coagulant.

- The milk coagulating property of the fruits is attributed to the pulp and husk berries which contain an enzyme called Withanin, having milkcoagulating activity.

- One ounce of the fruits of W. coagulans when mixed with 1 quart of boiling water makes a decoction, one table spoonful of which is capable to coagulate a gallon of milk in just an hour. In Pakistan, the berries of W. coagulans are commonly used to clot milk which is called, 'paneer'. The milk of buffalo or sheep is boiled to $100 \mathrm{oF}$ and treatedwith crushed berries of the plant, tied in a cloth. This causes the milk to curdle within 30-40 minutes.

- Treatment with coagulanolide4 along with four known withanolides 1-3 and 5 isolated from W. coagulans fruits, showed significant inhibition on postprandial rise in hyperglycemia post-sucrose load in normoglycemic rats as well as streptozotocininduced diabetic rats.

- The compound 5 also caused significant fall in fasting blood glucose profile and improved the glucose tolerance of $\mathrm{db} / \mathrm{db}$ mice. Further, compound 5 showed antidyslipidemic activity in $\mathrm{db} / \mathrm{db}$ mice.

- The median effective dose of the compound 5 was determined to be around $25 \mathrm{mg} / \mathrm{kg}$ body weight in streptozotocin-induced diabetic rats, which is comparable to the standard antidiabetic drug metformin.

This explains the traditional use of $\mathrm{W}$. coagulans as antihyperglycemic cum antidyslipidemic agent by the traditional medical practitioners

\section{Treatment Data}

- The dose of $1000 \mathrm{mg} / \mathrm{kg}$ was identified as the most effective dose, which reduces the Fasting Blood Glucose level maximum by $33.2 \%$ at $4 \mathrm{~h}$ in normal rats during fasting blood glucose studies.

- Glucose tolerance test studies of normal, sub and mild diabetic rats showed the maximum reduction of 15.7, 28.9 and $37.8 \%$ at $3 \mathrm{~h}$ respectively. Long-term study in case of severely diabetic rats showed reduction of 52.9 and $54.1 \%$ in Fasting Blood Glucose and Post Prandial Glucose levels respectively after 30 days of treatment.

- The present study, besides confirming hypoglycemic and antidiabetic activities of aqueous extract of W. coagulans, helps in identifying the role of trace minerals like $\mathrm{Mg} \& \mathrm{Ca}$ responsible for antidiabetic potential of this potent indigenous shrub.

These study are based on results of lowering in blood glucose levels of normal, sub, mild diabetic rats assessed during fasting blood glucose, glucose tolerance test studies.

The dose of $200 \mathrm{mg} / \mathrm{kg}$ was identified as the most effective dose, which reduce the blood glucose level maximum by $35.2 \%$ at 5 hours in normal rats during blood glucose studies.

Glucose tolerance test studies is normal, sub and mild diabetic rats showed the maximum reduction of $16.7,29.8$ and $38.5 \%$ at 4 hour respectively.

Long term study in case of severely diabetic rats showed reduction fasting glucose level respectively after 30 days of treatment.

The present study confirming antidiabetic effect of aqueous extract of Withania Coagulans, helps in identifying the role of trace minerals like $\mathrm{Mg}$ and $\mathrm{Ca}$ 
responsible for antidiabetic potential of this potent indigenous shrub.

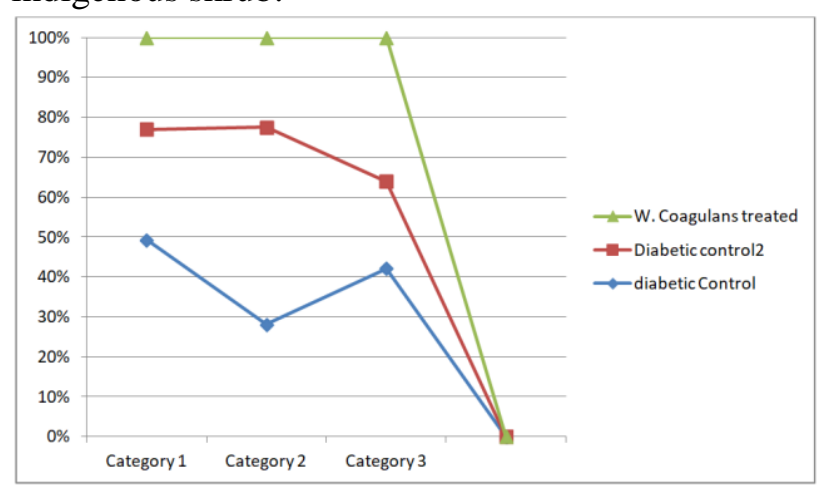

Figure 1: Effect of Withania Coagulans on blood glucose level diabetic treated rats showed significant decrease in blood glucose levels compared to diabetic controls.

\section{Discussion}

Diabetes Mellitus leads to many chronic/potential complications such as blindness, heart disease, nerve damage and renal failure, etc.

The study revealed that 108 plant species belonging to 56 families were generally used for treatment of diabetes. The majority of the experiments confirmed the benefits of medicinal plants with hypoglycemic effects in the management of diabetes mellitus. Among the plants used for the diabetes, Annona squamosa, Momordica charantia, Egyptian Morus alba, Lycium barbarum, Allium sativum, and Aegle marmelose seems to be most common plants used to treat diabetes and are available everywhere. The detailed natural plants not only used for the treatment of diabetes, but also treated for other ailments also. The fruits were most commonly used plant parts and other parts (leaf, root, stem, bark, flower, and whole plant) were also useful for curing.

\section{Authors Contribution}

Authors who contributed significantly read, and approved the paper are yogesh kumar Sharma, mayank bansal, anil kumar who conceived and designed the experiments.

\section{Conclusion}

Antidiabetic plants used in the treatment of diabetes mellitus. These cost effective management of diabetes through dietary interventions, nutrient supplementation, and combination therapies with synthetic drugs in the short term, and as the sole medication from natural sources over the long term. The presences of bioactive chemicals are mainly responsible for this antidiabetic action. However, many other active agents obtained from plants have not been well characterized. More investigations must be carried out to evaluate the mechanism of action of medicinal plants with antidiabetic effect.

\section{Reference}

1. Goodman and Gilman's.,"The pharmacological basis of therapeutics."10th Ed.,Mcgraw-Hill Prakashan, New Delhi,2001,1679-1714.

2. Tripathi K.D.,'Essential of Medical Pharmacology." 5thEd.,Jaypee Brother Pvt.Ltd.,New Delhi,2003,233-253.

3. Diabetes mellitus: http://www. en.wikipedia. org/wiki/diabetes.html on 10/05/18

4. Soumyanatha A.," Traditional Medicine for Modern Times: Antidiabetic Plants." Taylor and Francis Group,2006,19-61.

5. Borassus flabellifer: http://www. raintree.com/cormama./tropical plant database.html on $09 / 02 / 20$

6. Kirtikar, K.R. and Basu,'Indian Medicinal Plants." Vol. I - IV. 2nd Ed. Jayyed Press, New Delhi, B. D. 1975.

7. Singh V. and Pandey R. P., "Ethnobotany of Rajasthan," Scientific Publishers, India, 1998.

8. Paranjape P., "Indian medicinal Plants: Forgotten herbs," , Chaukhamba Sanskrit Prathisthan,New Delhi, 2007.

9. P. Zimmet, K. G. M. M. Alberti, and J. Shaw, "Global and societal implications of the diabetes epidemic," Nature, vol. 414, no. 6865 , pp. 782-787, 2001.View at: Publisher Site

10. L. Rossetti, A. Giaccari, and R. A. DeFronzo, "Glucose toxicity," Diabetes Care, vol. 13, no. 6, pp. 610-630, 1990.View at: Publisher Site | Google Scholar.

11. Hemalatha S, Wahi A K Singh PN and Chansouria J P. Hypoglycemic activity of Wuthania Coagulans Dunal in streptozotocin induced diabetic rats. J Ethnopharmacol.93(23): 2004, 261-264.

12. Budhiraja R D, Sudhir S and Garga K N Pharmacological investigations on fruits of Withania coagulans Dunal. Planta Med 32: 1977, 154-157.

13. Jaiswal D, Rai P K and Watal G. Antidiabetic effect of Withania coagulans in experimental rats. Indian Journal of Clinical Biochemistry, 24(1): 2009, 88-93.

14. Budhiraja RD, Bala S, Craeg FN, Arora B. Protective effect of 3-beta-hydroxy-2-3 dihydro withanolide-F against $\mathrm{CCl} 4$ induced hepatotoxicity. Planta Medica 1986; 1: 28-9.

15. Rajurkar SM, Thakre PN, Waddukar SG. Phytochemical and pharmacological screening of Withania coagulans berries as 
antiinflammatory. 53 IPC 2001, New Delhi, Dec., Sci. Abst CP38, 2001; p. 215.

16. Hemalatha S, Sachdeva N, Wahi AK, Singh PN, Chansouria JPN. Effect of aqueous extract of fruits of Withania coagulans on glucose utilization by rat hemidiaphragm. Ind $\mathbf{J}$ Nat Prod 2005; 21(2): 20-21.

17. Brahm D, Trinder P. Estimation of glucose by glucose oxidase method. Analyst 1972; 97: 142-5.
18. Sabsabi M, Cielo P. Quantitative analysis of aluminum alloys by laser-induced breakdown spectroscopy and plasma characterization Appl Spectrosc 1995; 49(4): 499-507.

19. Kar A, Choudhary BK. Important mineral content of a few ayurvedic herbs with a discussion on medicinal aspects. Indian Drugs 1994; 31(3): 127-30. 